\title{
Correction to: Switching from natalizumab to fingolimod treatment in multiple sclerosis: real life data from the Austrian MS Treatment Registry
}

\author{
Michael Guger ${ }^{1}$. Christian Enzinger ${ }^{2}$ - Fritz Leutmezer ${ }^{3}$. Jörg Kraus ${ }^{4,5}$. Stefan Kalcher ${ }^{6}$. Erich Kvas ${ }^{7}$. \\ Thomas Berger ${ }^{3}$. on behalf of the Austrian MS Treatment Registry (AMSTR)
}

Published online: 17 September 2019

(c) Springer-Verlag GmbH Germany, part of Springer Nature 2019

\section{Correction to: Journal of Neurology https://doi.org/10.1007/s00415-019-09464-0}

The original version of this article unfortunately contained a mistake. First and last names of the authors were interchanged. The correct author names are given below.

Michael Guger · Christian Enzinger · Fritz Leutmezer · Jörg Kraus · Stefan Kalcher · Erich Kvas · Thomas Berger

The original article has been corrected.

The original article can be found online at https://doi.org/10.1007/ s00415-019-09464-0.

Michael Guger

Michael.Guger@kepleruniklinikum.at

1 Clinic for Neurology 2, Med Campus III, Kepler University Clinic, Krankenhausstrasse 9, 4021 Linz, Austria

2 Department of Neurology, Medical University of Graz, Graz, Austria

3 Department of Neurology, Medical University of Vienna, Vienna, Austria

4 Department of Laboratory Medicine, Paracelsus Medical University and Salzburger Landeskliniken, Salzburg, Austria

5 Department of Neurology, Medical Faculty, Heinrich-Heine-University, Düsseldorf, Germany

6 Hermesoft, Data management, Graz, Austria

7 Hermesoft, Statistics, Graz, Austria 